\title{
Special Article
}

\section{Defining rules for the identification of critical ventilatory events}

\author{
[Définition de règles pour identifier les événements respiratoires critiques]
}

J. Mark Ansermino fRCPC, Maryam Dosani bsc, Erica Amari BA, Peter T. Choi MD FRCPC MSc, Stephan K. W. Schwarz MD PhD FRCPC

Purpose: The automated recognition of critical clinical events by physiological monitors is a challenging task exacerbated by a lack of standardized and clinically relevant threshold criteria. The objective of this investigation was to develop consensus for such criteria regarding the identification of three ventilatory events: disconnection or significant leak in the anesthesia circuit, decreased lung compliance or increased resistance, and anesthetic overdose from inhaled anesthetics.

Methods: We individually administered a structured interview to five expert anesthesiologists to gain insight into the cognitive processes used by clinicians to diagnose ventilatory events and to determine the common heuristics (rules of thumb) used in clinical practice. We then used common themes, identified from analysis of the structured interviews, to generate questions for a series of web-based questionnaires. Using a modified Delphi technique, iterative questionnaire administration facilitated rapid consensus development on the thresholds for the specific rules used to identify ventilatory events.

Results: A threshold for $75 \%$ agreement was described for each scenario in a healthy ventilated adult. A disconnection or significant leak in the anesthesia circuit is diagnosed with peak airway pressure ( $<5 \mathrm{~cm} \mathrm{H}_{2} \mathrm{O}$ or change of $15 \mathrm{~cm} \mathrm{H}_{2} \mathrm{O}$ ), ETCO $(0 \mathrm{mmHg}, 40 \%$ drop, or value below $10 \mathrm{mmHg}$ for a duration of $20 \mathrm{sec})$, and inspired-expired volume difference $(300 \mathrm{~mL})$.
Increased resistance or decreased lung compliance is diagnosed

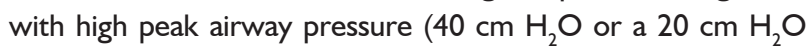
change), asymmetry of capnogram, and changes in measured compliance or resistance. Anesthetic overdose from inhaled anesthetics is diagnosed with high end-tidal anesthetic agent concentration (2 MAC in a patient less than $60 \mathrm{yr}$ of age or 1.75 MAC in a patient over $60 \mathrm{yr}$ of age), low systolic blood pressure (below $60 \mathrm{mmHg}$ ), and low modified electroencephalogram (bispectral index or entropy).

Conclusion: This investigation has provided a set of consensusbased criteria for developing rules for the identification of three critical ventilatory events and has presented insight into the decision heuristics used by clinicians.

CAN J ANESTH 2008/55: $10 /$ pp 702-714

Objectif : La reconnaissance automatisée des événements cliniques critiques par des moniteurs physiologiques constitue un défi rendu difficile par le manque de critères de seuils standardisés et pertinents d'un point de vue clinique. L'objectif de cette étude était de parvenir à un consensus par rapport aux critères nécessaires à l'identification de trois événements respiratoires : une déconnexion

From the Department of Anesthesiology, Pharmacology \& Therapeutics, The University of British Columbia, Vancouver, British Columbia, Canada.

Address correspondence to: Dr. J. Mark Ansermino, British Columbia Children’s Hospital, Department of Pediatric Anesthesia, Room 1L7, 4480 Oak Street, Vancouver V6H 3V4, Canada. E-mail: anserminos@yahoo.ca

Support has been provided by an operating grant (MOP - 79418) from the Canadian Institutes of Health Research, and the Canadian Anesthesiologists' Society. Mark Ansermino is a Michael Smith Foundation for Health Research Scholar, has received operating grants from the Natural Sciences and Engineering Research Council of Canada, and has a research agreement with Draeger Medical for research unrelated to this project. Mark Ansermino is co-recipient of operating grants from the Canadian Institutes of Health Research, the Natural Sciences and Engineering Research Council of Canada, the Michael Smith Foundation for Health Research, and the Child \& Family Research Institute. Stephan Schwarz and Mark Ansermino are recipients of a Canadian Anesthesiologists' Society/Abbott Laboratories Ltd Career Scientist Award in Anesthesia. Stephan Schwarz holds an independently peer-reviewed research grant sponsored by Pfizer Canada, unrelated to this research, and is co-recipient of operating grants from the Natural Sciences and Engineering Research Council of Canada and the Canadian Institutes of Health Research. There are no commercial or non-commercial affiliations that were, or might be perceived to be, a conflict of interest for the other authors.

Accepted for publication May 1, 2008.

Revision accepted July 5, 2008.

This article is accompanied by an editorial. Please see Can J Anesth 2008; 55: 670-3. 
ou une fuite considérable du circuit anesthésique, une compliance pulmonaire diminuée ou une résistance accrue, et une overdose anesthésique résultant des anesthésiques inhalés.

Méthode: Nous avons individuellement mené des entretiens structurés de cinq anesthésiologistes experts afin d'avoir un aperçu des processus cognitifs utilisés par les cliniciens pour dépister les événements respiratoires et de déterminer les connaissances heuristiques communes (règle empirique) utilisées dans la pratique clinique. Ensuite, nous nous sommes servis des thèmes communs identifiés par l'analyse des entretiens structurés afin de générer des questions pour une série de questionnaires en ligne. À l'aide d'une méthode de Delphi modifiée, l'administration itérative des questionnaires a permis le développement rapide d'un consensus concernant les seuils pour les règles spécifiques utilisées dans l'identification des événements respiratoires.

Résultats : Pour chaque scénario chez un adulte sain ventilé, un seuil de concordance de $75 \%$ a été décrit. Une déconnexion ou fuite considérable du circuit anesthésique est diagnostiquée lors d'une pression maximale du conduit aérien $\left(<5 \mathrm{~cm} \mathrm{H}_{2} \mathrm{O}\right.$ ou changement de $\left.15 \mathrm{~cm} \mathrm{H}_{2} \mathrm{O}\right), \mathrm{ETCO}_{2}(0 \mathrm{mmHg}$, chute de $40 \%$, ou valeur en dessous de $10 \mathrm{mmHg}$ pour une durée de $20 \mathrm{sec}$ ), et d'une différence de volume inspiré-expiré (300 mL). Une résistance accrue ou une compliance pulmonaire réduite est diagnostiquée lors d'une pression maximale du conduit aérien élevée $\left(40 \mathrm{~cm} \mathrm{H}_{2} \mathrm{O}\right.$ ou un changement de $20 \mathrm{~cm} \mathrm{H}_{2} \mathrm{O}$ ), un capnogramme asymétrique, et de changements dans la compliance ou la résistance mesurées. Une overdose anesthésique provoquée par les anesthésiques inhalés est diagnostiquée lors d'une concentration d'anesthésique télo-expiratoire élevée (2 MAC chez un patient de moins de 60 ans ou I,75 MAC chez un patient de plus de 60 ans), de pression systolique basse (inférieure à $60 \mathrm{mmHg}$ ) et d'électroencéphalogramme modifié bas (index bispectral ou moniteur entropy).

Conclusion : Cette étude a permis de déterminer un ensemble de critères basés sur un consensus pour le développement de règles permettant l'identification de trois événements respiratoires critiques et a donné un aperçu des connaissances heuristiques utilisés par les cliniciens pour prendre des décisions cliniques.

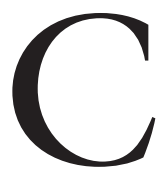
ritical decision making is important to the anesthesiologist who must respond quickly and appropriately to perioperative events. Information used in the decision-making process is derived from the clinician's observations of the patient and the environment, along with physiological data delivered by visual (monitor display) and auditory (sonification and alarms) sensory modalities. This vast amount of information is continuously and instantaneously processed, in conjunction with personalized heuristics (rules of thumb), to identify critical clinical events. Whereas the reliance upon personalized heuristics may suffice for the experienced anesthesiologist, it presents a challenge in research as well as in the development of new technologies designed to assist the anesthesiologist in processing large quantities of information.

Standardized rules for the identification of clinical events may subsequently be translated into clinical triggers (automated reminders) that can be displayed, along with relevant information, to facilitate clinical diagnosis or treatment (just-in-time information). Cognitive aids, already prevalent in the aviation industry, have recently been developed to cue physicians to previously learned information and to help clinicians adhere to established protocols. ${ }^{1}$ For example, an aid developed by the Veterans Health Administration's National Centre for Patient Safety to help anesthesiologists manage rare, high-mortality adverse events has been reported to be helpful in both emergency and non-emergency situations. ${ }^{2}$ Ideally, these cognitive aids would be integrated electronically into the workflow of the anesthesiologist and would be automatically triggered when adverse events occur. Effective integration of cognitive aids requires that clinical monitoring systems first achieve an appropriate balance between the creation of false alarms (specificity) and the risk of missing an event (sensitivity).

Current clinical monitoring systems are conventionally programmed to generate alarms based on fixedthreshold limits of a single variable. False alarms are inevitable and result from both natural fluctuations of physiological rhythms over time and the variation in acceptable physiological parameters for each patient. Clinical interventions and artifacts, resulting from interference generated by electrocautery or patient movement, exacerbate the occurrence of false alarms. ${ }^{3}$ As such, more than $90 \%$ of alarms currently generated in the clinical environment can be dismissed as insignificant, with a third of these being triggered by artifacts.

In contrast, clinicians combine clinical experience, published evidence, training, and, most importantly, the observed pattern of multiple variables or observed changes in a single variable over time, to identify critical clinical events. In daily practice, anesthesiologists must process and integrate explicit knowledge (formal theoretical learning) and tacit (personal) knowledge ${ }^{4}$ to make rapid decisions in the interest of patient safety. However, as with most experts, they are not aware of the means by which tacit knowledge is gained or used. ${ }^{5}$ Initiatives to facilitate the evolution of tacit knowledge into explicit knowledge are integral to the advancement of medical knowledge. ${ }^{6}$

In recognition of the need to document the tacit knowledge of anesthesiologists, we have undertaken 
a systematic process to define threshold criteria for critical clinical events that incorporates both structured interviews and consensus development using the Delphi technique. ${ }^{7}$ In the present study, our aim was to identify the thresholds in clinical monitoring that clinicians use for the identification of three ventilatory events: disconnection or significant leak in the anesthesia circuit, decreased lung compliance or increased resistance, and anesthetic overdose from inhaled anesthetics.

\section{Methods}

Approvals for this study were obtained from the University of British Columbia and the British Columbia Children's and Women's Hospital Clinical Research Ethics Boards. Informed consent was obtained from each participant.

We used a two-phase approach to identify and obtain consensus for criteria for the diagnosis of the three ventilatory events. In the first phase, structured interviews were conducted with clinicians to gain insight into the cognitive processes typically used to diagnose these events and to determine the common heuristics used in clinical practice. In the second phase, a web-based series of questionnaires was administered, based on a modified Delphi technique, to determine consensus on each specific rule criterion.

\section{Structured interviews}

An anesthesiologist investigator and a research assistant conducted the structured interviews. The participants were asked a fixed set of open-ended questions to determine the key clinical criteria used to identify each selected clinical condition and to explore the boundaries between normal and abnormal patient conditions. Opinions were elicited regarding the identification of ventilatory events and the participants' prior experience (personal or institutional) with each event. Each interview was recorded and transcribed, and the data were analyzed for common themes using ATLAS/ti (T. Muhr, Germany, 1994). After the data were fully coded, annotated, and categorized, frequencies of codes were tabulated. Tabulations were used to construct a framework of rules used to describe the identification of ventilatory events. This framework incorporated key features of the ventilatory events, maximum and minimum variable limits, limits of change, and the interaction of two or more physiological variables.

\section{Delphi technique}

The Delphi technique was developed as a way to assess the judgment of experts. Characterized by a cycle of item generation, followed by endorsement and iterative feedback of anonymous group responses, the technique has been used in a wide variety of settings, including anesthesiology ${ }^{8}$ to achieve group consensus without a face-to-face meeting. The technique ensures that the impact of dominant participants and group pressure towards consensus are minimized. The technique was modified for this study to determine thresholds for single and combinations of physiological variables. A range of response options was provided for each questionnaire item. We used a two-stage technique to avoid response fatigue.

The interview data for each ventilatory event were used to create individual questionnaires designed to refine the rules identified in the original interviews. Each questionnaire contained eight to 28 multiplechoice items, each with three to seven response options. We also included one to two items in each questionnaire which asked participants to rank the available response options in terms of how applicable each choice response would be in the identification of the respective ventilatory event. The web-based questionnaires were created using the Quask FormArtist program (Quask AG, Zurich, Switzerland) and were hosted on a secure server for online administration.

To recruit participants for the Delphi technique, an electronic mail request was sent to individual anesthesiologists in 11 different institutions across Canada. Selection of participants was based on the availability of e-mail addresses of these anesthesiologists. The sample size was chosen in order to achieve 20 responses for each of the two rounds of the questionnaires. The e-mail included a description of the study and an automated link to the online questionnaire. The link directed the participant to the consent page, which had to be completed before the participant could proceed to the five- to ten-minute questionnaire. By means of a unique identifier in the web link, participants were restricted from submitting more than one response per question. Participants were given one week to complete the questionnaire. Two reminders were sent to participants who had not responded by days six and seven.

An identical questionnaire was administered to the same participants in the second round. The participants were permitted to adjust their previous response on the basis of the median response of the group. The median responses of all participants and the individual's previous response for each item were included for reference, as well as the overall ranking for ranking items. This overall ranking was determined by summing the ranks assigned to each response option in the first round. 
Statistical analyses of results from the Delphi technique vary widely according to the level of measurement utilized. Controlled feedback often includes measures of central tendency and of dispersion; however, care must be exercised in selecting measures appropriate for ordinal or nominal data. ${ }^{9}$ The final analysis commonly identifies convergence or change in participant response. Complex analytic models, perhaps applicable to certain Delphi questionnaires, have been proposed for the analysis of ordinal data. ${ }^{10,11} \mathrm{We}$ chose not to use these models, as we were attempting to find a threshold for each specific event rather than a single-response option. Following questionnaire administration, responses were collapsed to a threshold to achieve a $75 \%$ consensus in median responses. When the median lay between two response options, we chose the most clinically conservative response, which was dependent on the setting of the clinical observation. For example, if the median response fell between two threshold values of maximum peak airway pressure, the lower pressure threshold would be chosen. Conversely, when selecting a minimum threshold for blood pressure, the conservative choice would be the higher threshold value.

\section{Results}

\section{Structured interviews}

Five expert anesthesiologists, each with a minimum of five years experience, individually completed a 70-min structured interview. These anesthesiologists represented a diverse range of sub-specialties (adult [2], pediatric, cardiac, obstetric) and practiced at four different academic facilities in British Columbia. Common themes emerged from the structured interviews (Table I). In a healthy ventilated adult, a disconnection or significant leak in the anesthesia circuit is most commonly diagnosed by a change in the capnogram or spirometry loops, reduced peak airway pressure, reduced end-tidal $\mathrm{CO}_{2}$ levels $\left(\mathrm{ETCO}_{2}\right)$, decreased tidal volume, decreased positive end-expiratory pressure, decreased oxygen saturation $\left(\mathrm{SpO}_{2}\right)$, decreased inspired oxygen concentration, and lightening anesthesia. Increased resistance or decreased lung compliance is most commonly diagnosed by increased peak airway pressure, asymmetry of capnogram, and changes in tidal volume with a rise in $\mathrm{ETCO}_{2}$. An anesthetic overdose from inhaled anesthetics is most commonly diagnosed by high end-tidal anesthetic agent concentration, decreased systolic blood pressure, and low modified electroencephalogram (EEG) bispectral index (BIS), if available. Late signs of an anesthetic overdose would include bradycardia, hypoxemia, and ST segment depression.

\section{Delphi technique}

A total of $n=38$ anesthesiologists were approached to participate in the Delphi technique phase of this study. The sample represented a wide range of subspecialty training (cardiac [6], pediatric [10], obstetric [1], pain $[1])$ and included anesthesiologists from five Canadian provinces (Alberta [1], British Columbia [30], Manitoba [1], Ontario [4], Quebec [2]) practicing in academic [35] and non-academic [3] centres.

Of these, 36 anesthesiologists were invited to complete the questionnaire regarding disconnection or significant leak in the anesthesia circuit. Eighteen of these invitees did not complete the questionnaire, two completed the first round only, and 16 completed both rounds. Thirty-six anesthesiologists were invited to complete the questionnaire regarding decreased lung compliance or increased resistance. Fourteen of these invitees did not complete the questionnaire, four completed the first round only, and 18 completed both rounds. Thirty-seven anesthesiologists were invited to complete the questionnaire regarding anesthetic overdose from inhaled anesthetics. Thirteen of these invitees did not complete the questionnaire, two completed the first round only, and 22 completed both rounds.

For the questionnaire regarding disconnection or significant leak in the anesthetic circuit, $75 \%$ agreement was initially found for nine items and for another three items, after collapsing two response options. Decreased peak airway pressure $\left(<5 \mathrm{~cm} \mathrm{H}_{2} \mathrm{O}\right.$ or change of $\left.15 \mathrm{~cm} \mathrm{H}_{2} \mathrm{O}\right)$, low $\mathrm{ETCO}_{2}(0 \mathrm{mmHg}$, $40 \%$ drop, or value below $10 \mathrm{mmHg}$ for a duration of $20 \mathrm{sec}$ ), and inspired-expired volume difference $(300 \mathrm{~mL})$ are used to diagnose a leak or disconnection (Table II). For the questionnaire regarding decreased lung compliance or increased resistance, $75 \%$ agreement was initially found for three items and for another five items, after collapsing two response options. Peak airway pressure $\left(40 \mathrm{~cm} \mathrm{H}_{2} \mathrm{O}\right.$ or a 20 $\mathrm{cm} \mathrm{H}_{2} \mathrm{O}$ change), asymmetry of capnogram, and changes in measured compliance or resistance are used to diagnose decreased lung compliance or increased resistance (Table III). Agreement was more difficult to achieve regarding anesthetic overdose from inhaled anesthetics. For that questionnaire, $75 \%$ agreement was initially found for only two items. To achieve 75\% agreement, twelve items required the collapse of two response options and 16 items required the collapse of three or more response options. In a ventilated patient, end-tidal anesthetic agent concentration (2 $\mathrm{MAC}$ in a patient less than $60 \mathrm{yr}$ of age or $1.75 \mathrm{MAC}$ in a patient over $60 \mathrm{yr}$ of age), systolic blood pressure (below $60 \mathrm{mmHg}$ ), and low modified EEG (BIS or 


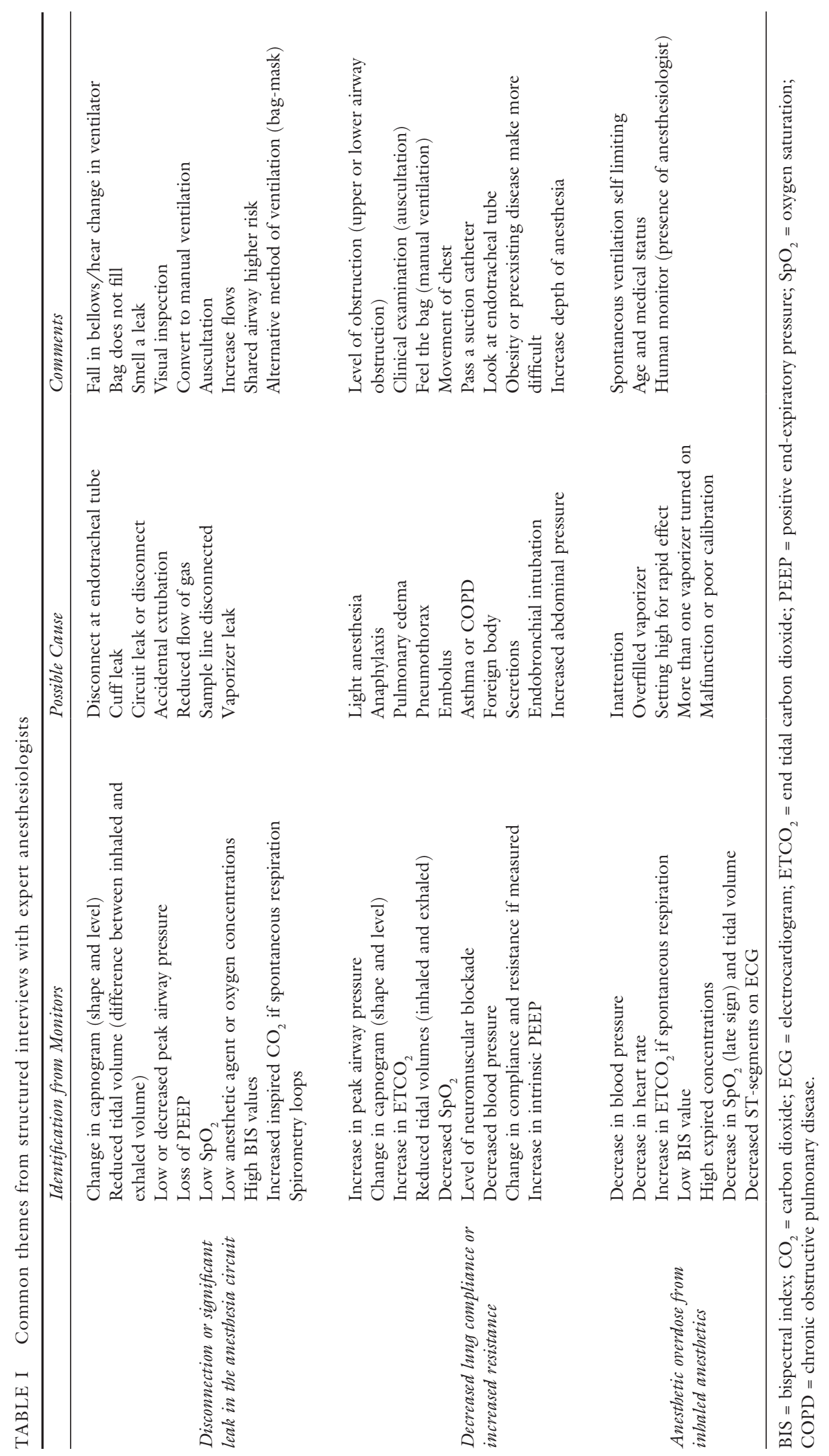




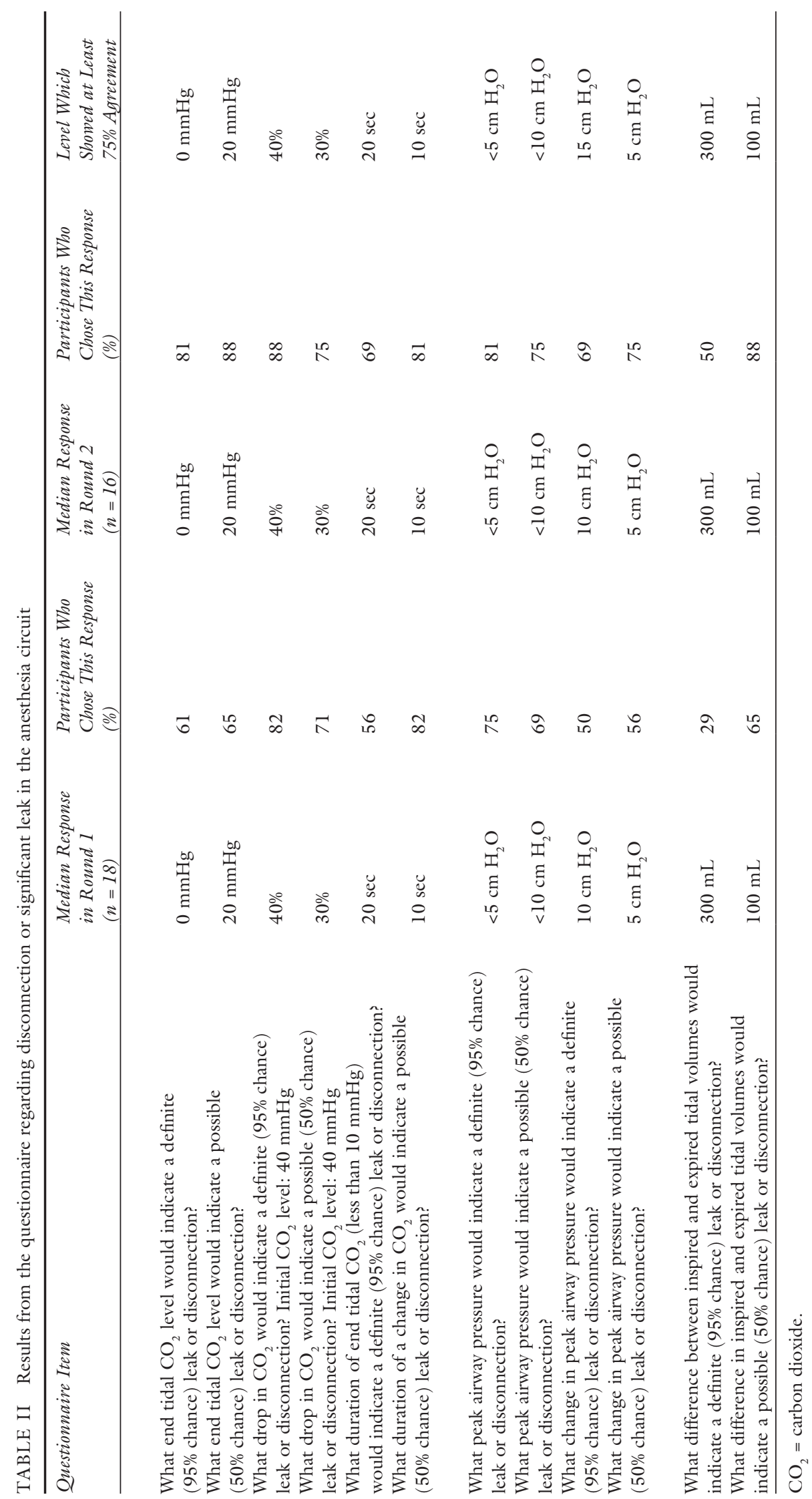




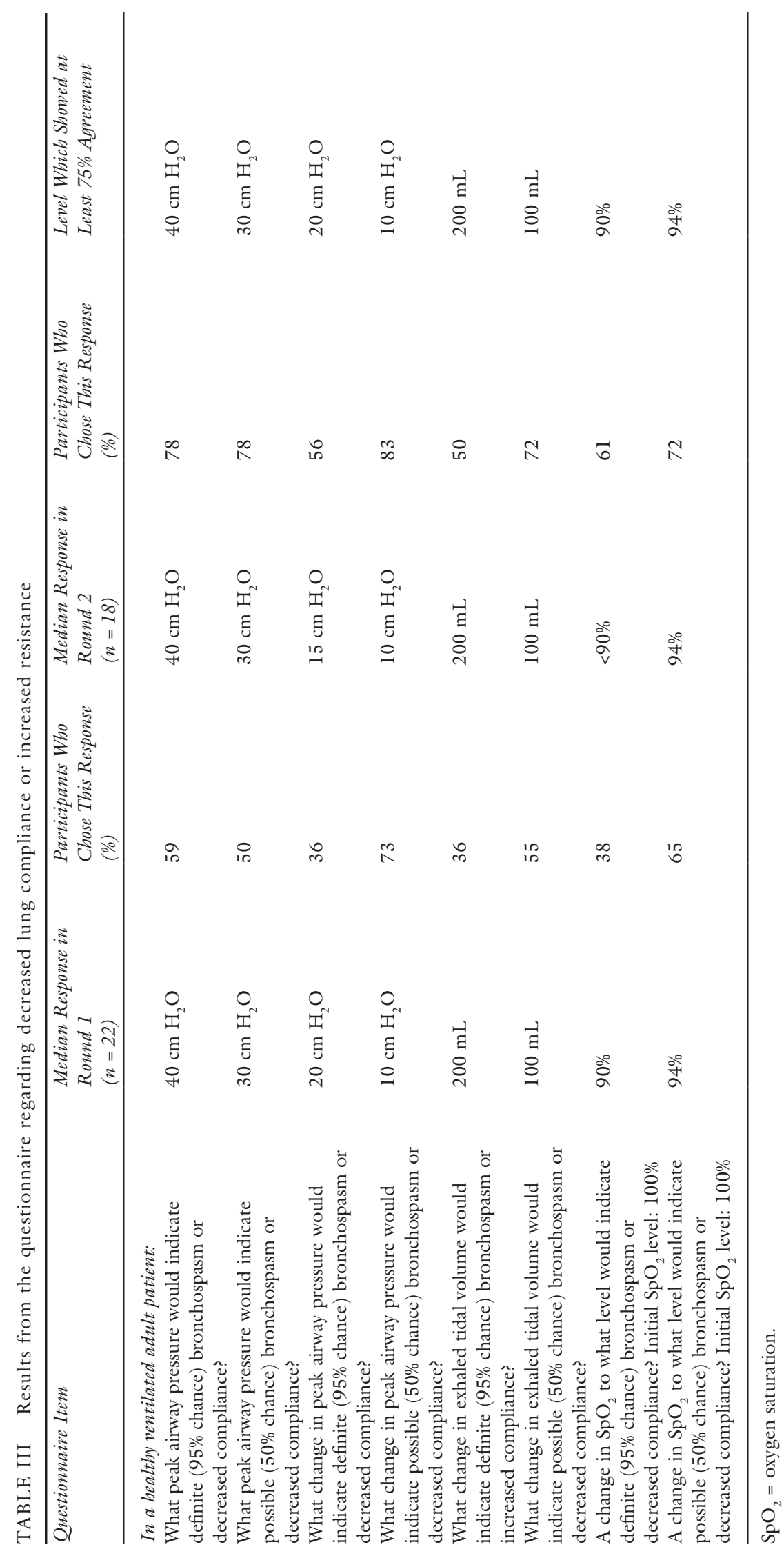




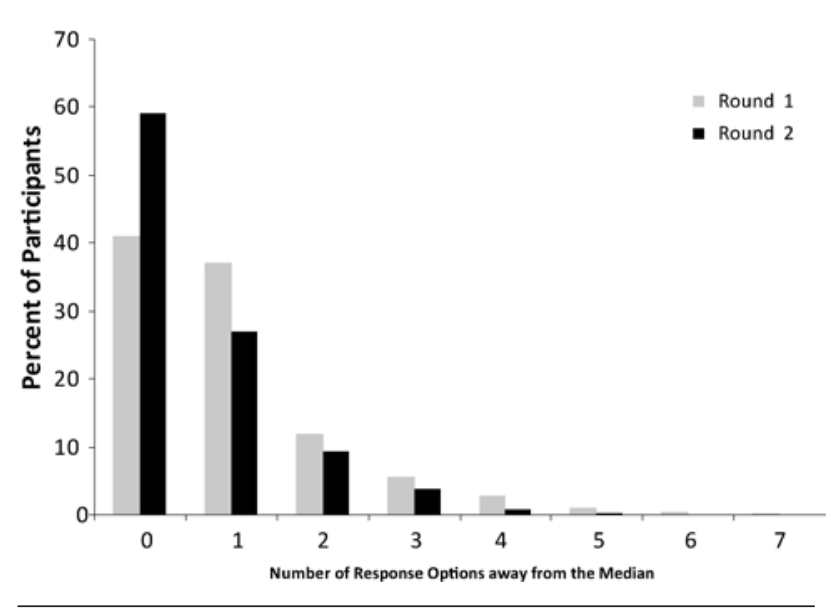

FIGURE Overall response distribution in rounds 1 and 2 of questionnaire administration.

Entropy) are used to diagnose an anesthetic overdose (Table IV). The results from the ranking items are presented in Table V. Summary tables include results from all submitted questionnaires after each round and include data from incomplete questionnaires. The overall response distribution showed markedly less deviation from the median in the second round of questionnaire administration (Figure).

\section{Discussion}

Using structured interviews and a modified Delphi technique, we have identified a set of threshold criteria for physiological monitors to identify three critical ventilatory events. In a healthy ventilated adult using a $3 \mathrm{~L} \cdot \mathrm{min}^{-1}$ fresh gas inflow rate, a definite or possible disconnection or significant leak in the anesthesia circuit is diagnosed by decreased $\mathrm{ETCO}_{2}$, drop in $\mathrm{ETCO}_{2}$ below $10 \mathrm{mmHg}$, duration of change in $\mathrm{ETCO}_{2}$, peak airway pressure, change in peak airway pressure, and difference between inspired and expired tidal volumes. A definite or possible decrease in lung compliance or increase in resistance is diagnosed by peak airway pressure, change in peak airway pressure, change in exhaled tidal volume, and change in $\mathrm{SpO}_{2}$. An anesthetic overdose from inhaled anesthetics in a healthy patient less than $60 \mathrm{yr}$ old or in a healthy patient over $60 \mathrm{yr}$ old is diagnosed by end-tidal anesthetic agent level, systolic blood pressure, and change in systolic blood pressure. The identified thresholds included the opinions of at least $75 \%$ of respondents. Agreement was easily achieved for more commonly used thresholds (e.g., peak airway pressure), but consensus on a single response for an item was much more difficult to achieve for percentage changes or for combinations of observations (e.g., agent concentration and blood pressure).

The responses highlight the difficulty in providing specific criteria for clinical events, as there is profound variability in "normal" physiological conditions, especially in what constitutes an anesthetic overdose. The likelihood that a specific event has occurred, based on the currently available information, is rarely absolute. More commonly, this likelihood follows a probability distribution, with the likelihood increasing as more information becomes available. As a wide range of response options were available, thresholds were determined by collapsing two or more response options. The failure to achieve agreement for a single response option reflects the uncertainly around defining specific thresholds rather than difficulties in reaching consensus. Caution should be exercised when adopting response options with a wider dispersion of responses into clinical practice.

The distinction between a normal and abnormal single value in an individual patient is complex. Individual clinicians often differ when making this distinction. As a result, the use of multiple definitions to describe a single event is commonly found in the literature, rendering research results difficult to compare. ${ }^{12}$ In a recent systematic literature review, the authors identified 140 different definitions of intraoperative hypotension. ${ }^{13}$ The application of these definitions to describe the same cohort of patients resulted in incidences ranging from $5 \%$ to $99 \%$. Universal definitions and agreement on explicit criteria in specific clinical situations is important for research purposes as well as for the development of standardized clinical guidelines.

Choosing a criterion that will distinguish normal from abnormal involves balancing the probability of creating a false alert with the risk of missing a critical event. Traditionally, physiological alarms are programmed with little or no tolerance for missed events (high sensitivity), which results in many false alerts (low specificity). This strategy can have a significant impact on human performance. False alerts reduce both compliance and reliance of clinicians on the alerting system, whereas missed events only impact clinicians' reliance. A decrease in reliance, without a decrease in compliance, may be advantageous. ${ }^{14}$

An alternative strategy for improving the performance of a criterion is to provide more information, either from a different source or from a different period in time. For example, an $\mathrm{ETCO}_{2}$ value of 30 $\mathrm{mmHg}$ is much more significant and informative if the value was $55 \mathrm{mmHg}$ two minutes previously. We did have a number of question items that attempted 


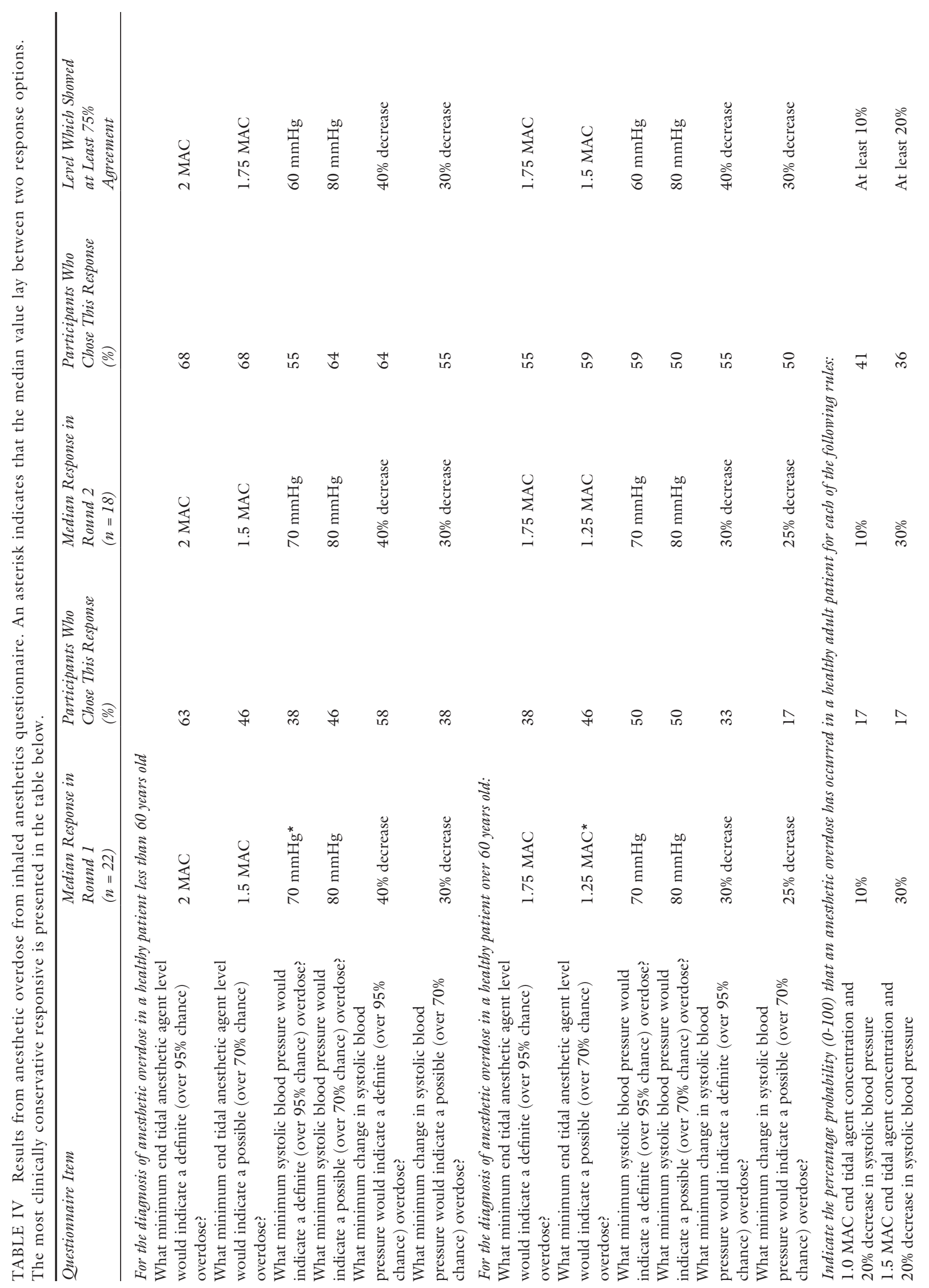




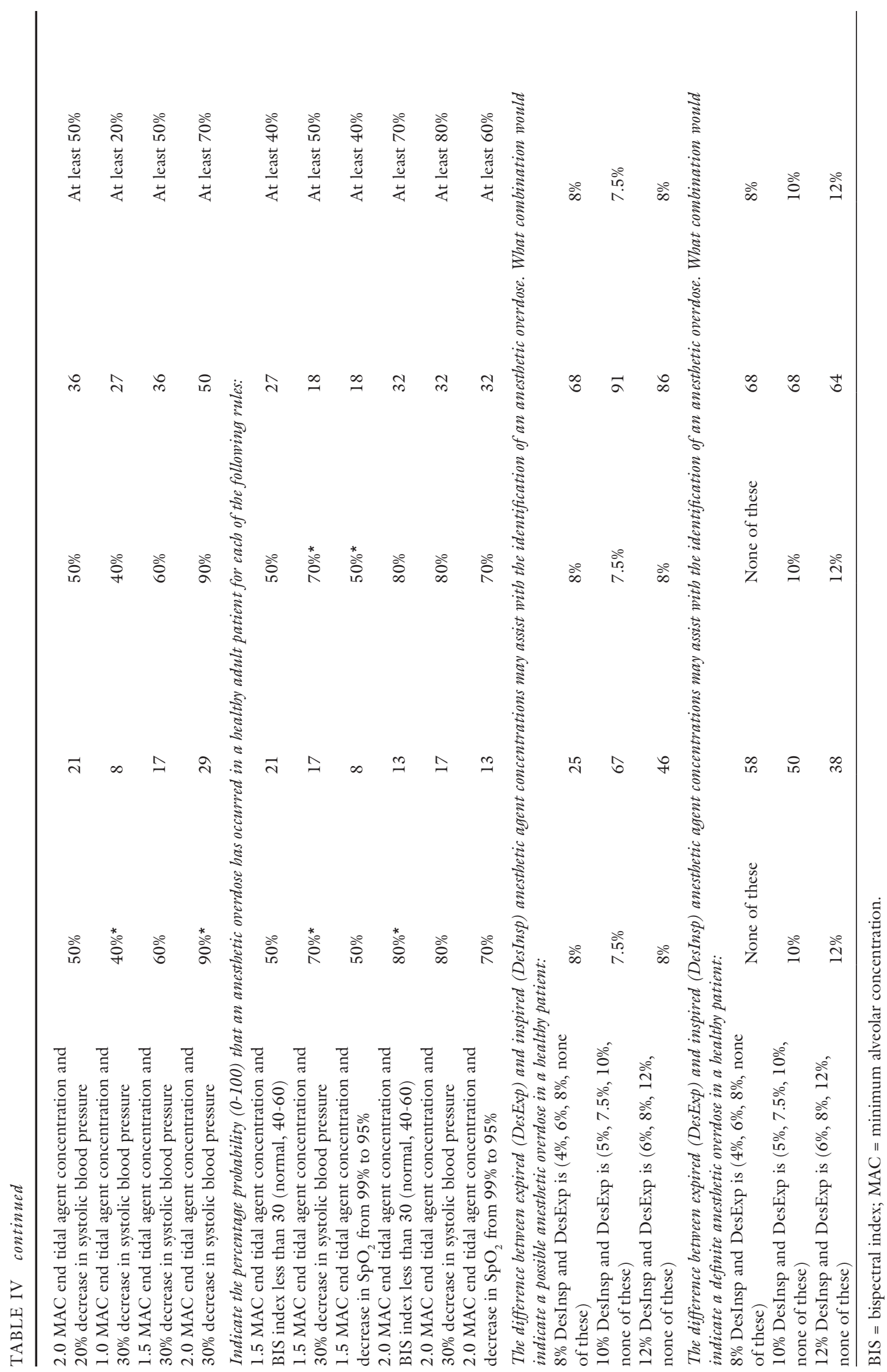




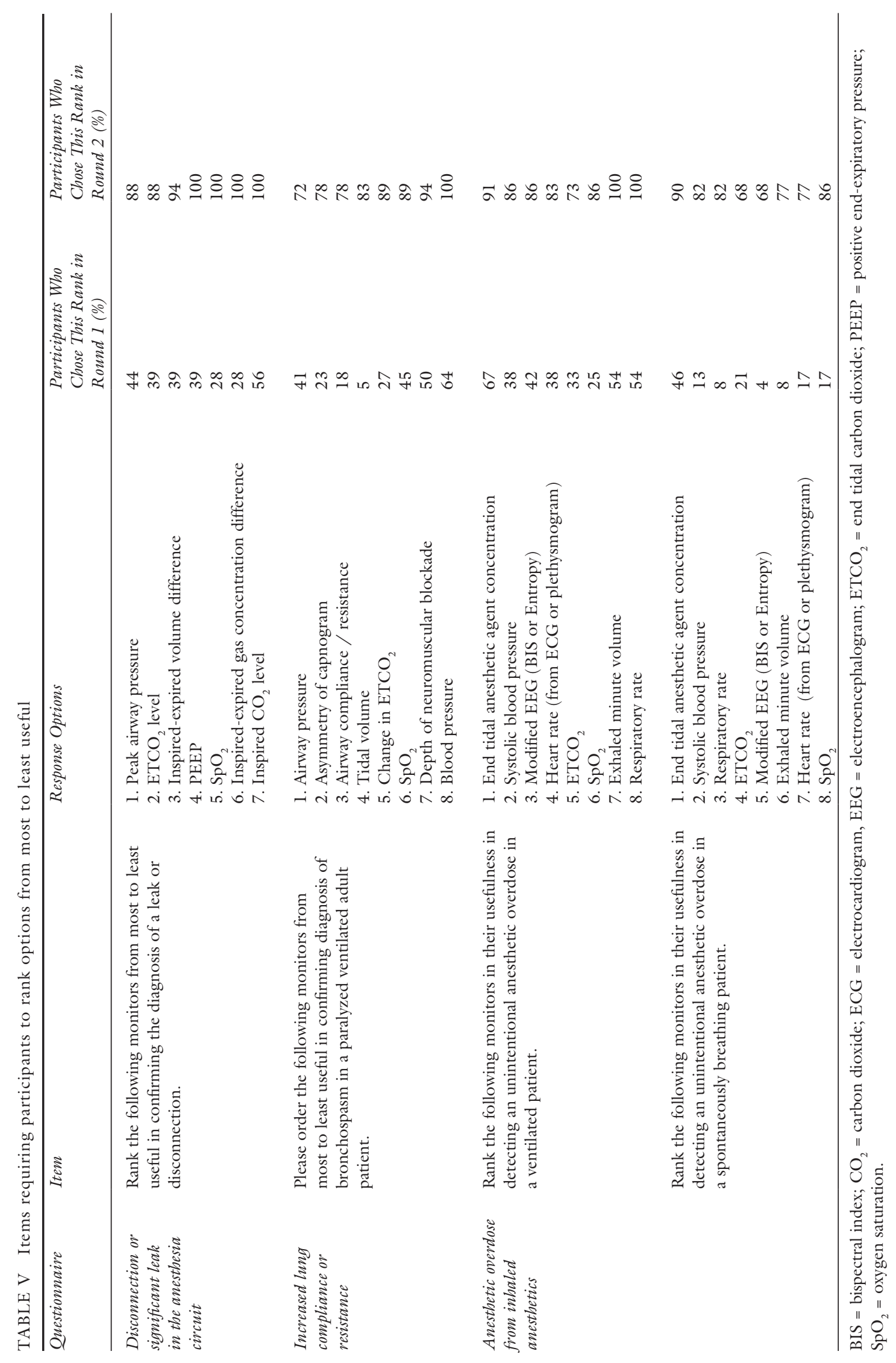


to look at the change in a variable over time. The consensus for these items tended to be much higher. This strategy would seem to be important for developing rules to identify ventilatory events.

To obtain the criteria and their threshold values for the three ventilatory events, we chose to use a modified Delphi technique over a consensus conference, as the former method permitted an adequately large number of clinicians to participate, feasibly across Canada, with an economical use of clinicians' limited and valuable time. However, there are limitations associated with the technique. The nature of feedback provided to participants in a Delphi questionnaire could influence the likelihood of reaching a consensus. ${ }^{15}$ In this study, the median responses of all participants and the individual's previous response for each item were presented to participants. The provision of additional feedback in the second round, regarding participant rationale and the range of responses for each item, may have influenced participants' subsequent responses. ${ }^{15}$ It is more likely that a consensus would have been reached if participants were presented with fewer response options or responses with a larger inter-response interval, but a reduction in response options would reduce the information conveyed by the participants. ${ }^{16}$ For this reason, we chose, instead, to collapse closely grouped options. Additionally, all participants were from Canadian institutions. Although we do not know the extent to which the rules identified in this study will be relevant to clinicians abroad, we anticipate that the identified rules will have broad applicability. The sample may not be fully representative of anesthesiologists across Canada, especially those practicing in non-academic centres. The number of participants was small, although the stability for this size of sample has been demonstrated. ${ }^{17}$ Finally, the response rate to the first round of questionnaires ranged from $47 \%$ to $65 \%$. This response rate is consistent with what is expected for web-based questionnaires, ${ }^{18}$ but it introduces the potential for response bias.

This investigation lays the groundwork for the establishment of rules for the identification of ventilatory events. Additional studies, in real-time clinical settings, are necessary to refine the identified rules, to quantify the proportion of false alarms or missed events that can be expected with the established rule base, and to validate the rules with regard to their clinical relevance and accuracy. This will assist in the development of decision support technology. We have recently released a decision support software tool ${ }^{19}$ that facilitates the collaborative development and sharing of rules.

The integration of expert systems into clinical prac- tice will also require the investigation of how experts work in their clinical domain ${ }^{20}$ followed by attempts to emulate the best performance in a machine. This will require an in-depth understanding of how clinicians work $^{21}$ as well as the identification of areas that might warrant improvement. Although many anesthesiologists do not see the benefit to using an expert system, ${ }^{22}$ clinicians are being increasingly challenged in their ability to process, integrate, and interpret the vast amount of available information resulting from rapid advances in sensor technology. Harnessing the ability of machines to rapidly process large amounts of data will inevitably lead to reduced patient risk.

This study highlights the challenges in reaching consensus regarding clinical criteria. These challenges reflect the uncertainty of the decisions made by clinicians every day in clinical practice, and the overlap between normal and abnormal measurements in specific clinical settings. Standardized terminology and clinically relevant definitions will improve comparison between research studies, will enhance guideline development, and will form the framework for clinical expert system development. This study has provided some insight into the decision heuristics used by clinicians in everyday clinical practice. We hope that this attempt to document the tacit knowledge of expert anesthesiologists will aid in establishing definitions that can become widely adopted by practicing clinicians.

\section{Acknowledgements}

We are greatly indebted to the anesthesiologists who have volunteered their time to participate in this study.

\section{References}

1 Hales BM, Pronovost PJ. The checklist-a tool for error management and performance improvement. J Crit Care 2006; 21: 231-5.

2 Neily J, DeRosier JM, Mills PD, Bishop MJ, Weeks WB, Bagian JP. Awareness and use of a cognitive aid for anesthesiology. Jt Comm J Qual Patient Saf 2007; 33: 502-11.

3 Koski EM, Makivirta A, Sukuvaara T, Kari A. Frequency and reliability of alarms in the monitoring of cardiac postoperative patients. Int J Clin Monit Comput 1990; 7: 129-33.

4 Smith A, Goodwin D, Mort M, Pope C. Expertise in practice: an ethnographic study exploring acquisition and use of knowledge in anaesthesia. $\mathrm{Br} \mathrm{J}$ Anaesth 2003; 91: 319-28.

5 Fish D, Coles C. Developing Professional Judgement in Health Care. London: Butterworth-Heinemann; 1998. 
6 Wyatt JC. Management of explicit and tacit knowledge. J R Soc Med 2001; 94: 6-9.

7 Adler M, Ziglio E. Gazing into the Oracle. The Delphi Method and its Application to Social Policy and Public Health. London: Jessica Kingsley Publishers 1996.

8 Morgan PJ, Lam-McCulloch J, Herold-McIlroy J, Tarshis $J$. Simulation performance checklist generation using the Delphi technique. Can J Anesth 2007; 54: 992-7.

9 Hasson F, Keeney S, McKenna H. Research guidelines for the Delphi survey technique. J Adv Nurs 2000; 32 : 1008-15.

$10 Q u \Upsilon$, Piedmonte $M R$, Medendorp SV. Latent variable models for clustered ordinal data. Biometrics 1995; 51 : 268-75.

11 Normand SL, McNeil BJ, Peterson LE, Palmer RH. Eliciting expert opinion using the Delphi technique: identifying performance indicators for cardiovascular disease. Int J Qual Health Care 1998; 10: 247-60.

12 Warner MA, Monk TG. The impact of lack of standardized definitions on the specialty. Anesthesiology 2007; 107: 198-9.

13 Bijker JB, van Klei WA, Kappen TH, van Wolfswinkel $L$, Moons KG, Kalkman CJ. Incidence of intraoperative hypotension as a function of the chosen definition: literature definitions applied to a retrospective cohort using automated data collection. Anesthesiology 2007; 107: 213-20.

14 Dixon SR, Wickens CD, McCarley JS. On the independence of compliance and reliance: are automation false alarms worse than misses? Hum Factors 2007; 49: 564-72.

15 Rowe G, Wright G. The Delphi technique as a forecasting tool: issues and analysis. Int J Forecasting 1999; 15: 353-75.

16 Johnson VE. On Bayesian analysis of multi-rater ordinal data: an application to automated essay grading. J Am Stat Assoc 1996: 91: 41-51.

17 Akins RB, Tolson H, Cole BR. Stability of response characteristics of a Delphi panel: application of bootstrap data expansion. BMC Med Res Methodol 2005; 5: 37.

18 Fricker RD, Schonlau JM. Advantages and disadvantages of internet research surveys: evidence from the literature. Field Methods 2002: 14; 347-67.

19 iKnow: Knowledge Authoring Tool [Internet]. Vancouver: University of British Columbia; c2007. Cited 2007 Nov 20; Available from URL; http://iknow.chii. ubc.ca (accessed June 2008).

20 Liu J, Wyatt J, Altman D. Decision tools in health care: focus on the problem, not the solution. BMC Med Inform Decis Mak 2006; 6: 4.
21 Smith AF, Mort M, Goodwin D, Pope C. Making monitoring 'work': human-machine interaction and patient safety in anaesthesia. Anaesthesia 2003; 58: 1070-8.

22 Beatty PC. User attitudes to computer-based decision support in anesthesia and critical care: a preliminary survey. The Internet Journal of Anesthesiology 1999; 3: 1 . 